\title{
Granule Cells in Aging Rats Are Sexually Dimorphic in Their Response to Estradiol
}

\author{
Phillippa Miranda, ${ }^{1,2}$ Christina L. Williams, ${ }^{3}$ and Gillian Einstein ${ }^{1,2}$ \\ ${ }^{1}$ Department of Neurobiology and 2Joseph and Kathleen Bryan Alzheimer's Disease Research Center, Duke University \\ Medical Center, Durham, North Carolina, 27710 and ${ }^{3}$ Department of Psychology: Experimental, Duke University, Durham, \\ North Carolina 27708
}

Normal aging comprises cognitive decline, including deterioration of memory. It has been suggested that this decline in memory is sexually dimorphic because of the cessation in gonadal steroid secretion that occurs during reproductive aging in female, but not male, mammals. We wondered whether neurons in brain regions associated with learning and memory underwent morphological changes that were dimorphic as well and whether cessation of the secretion of gonadal steroids influenced these morphological changes. To explore these questions, we deprived and restored estrogens to young and old gonadectomized females and males and studied the morphology of dentate granule cells by intracellular dye filling in a lightly fixed slice preparation. We found the following: (1) Aged female dentate granule cells deprived of gonadal steroids longterm have a paucity of dendritic spines compared with young females deprived short-term; however, aged male dentate

Memory decline is associated with normal aging in both rodents and humans (Rissenberg and Glanzer, 1986; Chiarello and Hoyer, 1988; Kadar et al., 1990; Youngjohn and Crook, 1993; Frick et al., 1995). In normal aging, female and male rat brains also undergo structural and functional changes, including loss and retraction of dendrites, spines, and myelin, as well as decreases in the density of receptor proteins and levels of neurotransmitters (Nunzi et al., 1987; Moroi-Fetters et al., 1989; Garcia-Segura et al., 1991). It has been suggested that, in females, memory loss is exacerbated by the decline in gonadal estrogens, marking reproductive senescence (rats) and menopause (humans) (Sulkava et al., 1985; Alliot and Giry, 1991). Conversely, replacement of estrogens protects against decline in memory in normal aging, as well as in Alzheimer's disease (Paganini-Hill and Henderson, 1994; Kimura, 1995; Henderson et al., 1996; O’Neal et al., 1996; Tang et al., 1996; Henderson, 1997; Kawas et al., 1997; Sherwin, 1997). These data suggest that the decrease in gonadal steroids that accompanies normal aging in females may accelerate agerelated cognitive decline by increasing the structural and functional changes to neurons in brain regions associated with learning and memory.

\footnotetext{
Received Nov. 12, 1998; revised Jan. 25, 1999; accepted Feb. 10, 1999.

This work was supported by American Foundation for Aging Research (to P.M.), National Institutes of Health (NIH) Grant AG09525 (to C.L.W.), NIH Grant P50AG05128 (Project 2), and Alzheimer's Association Grant IIRG-95136 (to G.E.). We thank Laurie Kennington for her technical assistance and Dr. Anthony LaMantia for helpful comments on this manuscript.

Correspondence should be addressed to Gillian Einstein, Box 3209, Duke University Medical Center, Durham, NC 27710.

Copyright (ㄷ) 1999 Society for Neuroscience $\quad 0270-6474 / 99 / 193316-10 \$ 05.00 / 0$
}

granule cells deprived of gonadal steroids long-term have no decrease in dendritic spines compared with young males deprived short-term. (2) Aged female dentate granule cells with long-term estrogen replacement at either high or low levels still had a decline in spine density. (3) Aged female dentate granule cells with short-term estradiol replacement had spine density increased to levels normally observed in young adults, whereas aged males with short-term estradiol replacement had decreased spine density. These data suggest that the response of rat dentate granule cells to aging and estradiol is sexually dimorphic and that, in females, the responsiveness of granule cells depends on the temporal pattern of estradiol replacement.

Key words: estrogens; aging; Alzheimer's disease; memory; dentate granule cells; hormone replacement therapy; dendritic spines; hippocampus; neuronal morphology

It is well established that estrogens can lead to an increase in neurite outgrowth, spine density, and synaptic input both in vitro (Toran-Allerand, 1976) and in vivo (Woolley and McEwen, 1992, 1993). Thus, we speculate that changes in estrogen availability and utilization by the brain of aging females enhances connectivity changes in aging female brains. To explore this possibility, we asked the following. (1) What is the morphology of neurons in estrogen-deprived aging females and males? (2) Does estrogen replacement in gonadectomized animals change this morphology? (3) Do morphological changes depend on the temporal pattern of estrogen replacement? We know already that, in the cycling female, CA1 pyramidal neurons undergo synaptic remodeling over the course of the estrous cycle but that under the same conditions dentate granule cells are unresponsive (Woolley and McEwen, 1992). However, because dentate granule cells lose spines quickly under other conditions, such as denervation caused by aging and disease (Nadler et al., 1973, 1977; White et al., 1979; Flood and Coleman, 1986; Flood et al., 1987; Einstein et al., 1994; Shetty and Turner, 1995), we wondered whether they would be responsive to estrogen deprivation and replacement in the aging animal.

In females, we mimicked different conditions of naturally occurring estrogen exposure during aging in humans and rats: "human menopause" by ovariectomizing female rats and providing no steroid replacement; "constant estrus" (as in aging rats) by providing a constant high-dose estradiol replacement to ovariectomized rats; and "persistent diestrus" (as in very old rats) by providing a constant low-dose estradiol replacement. Cyclical exposure to estrogens of young females was mimicked by injecting 

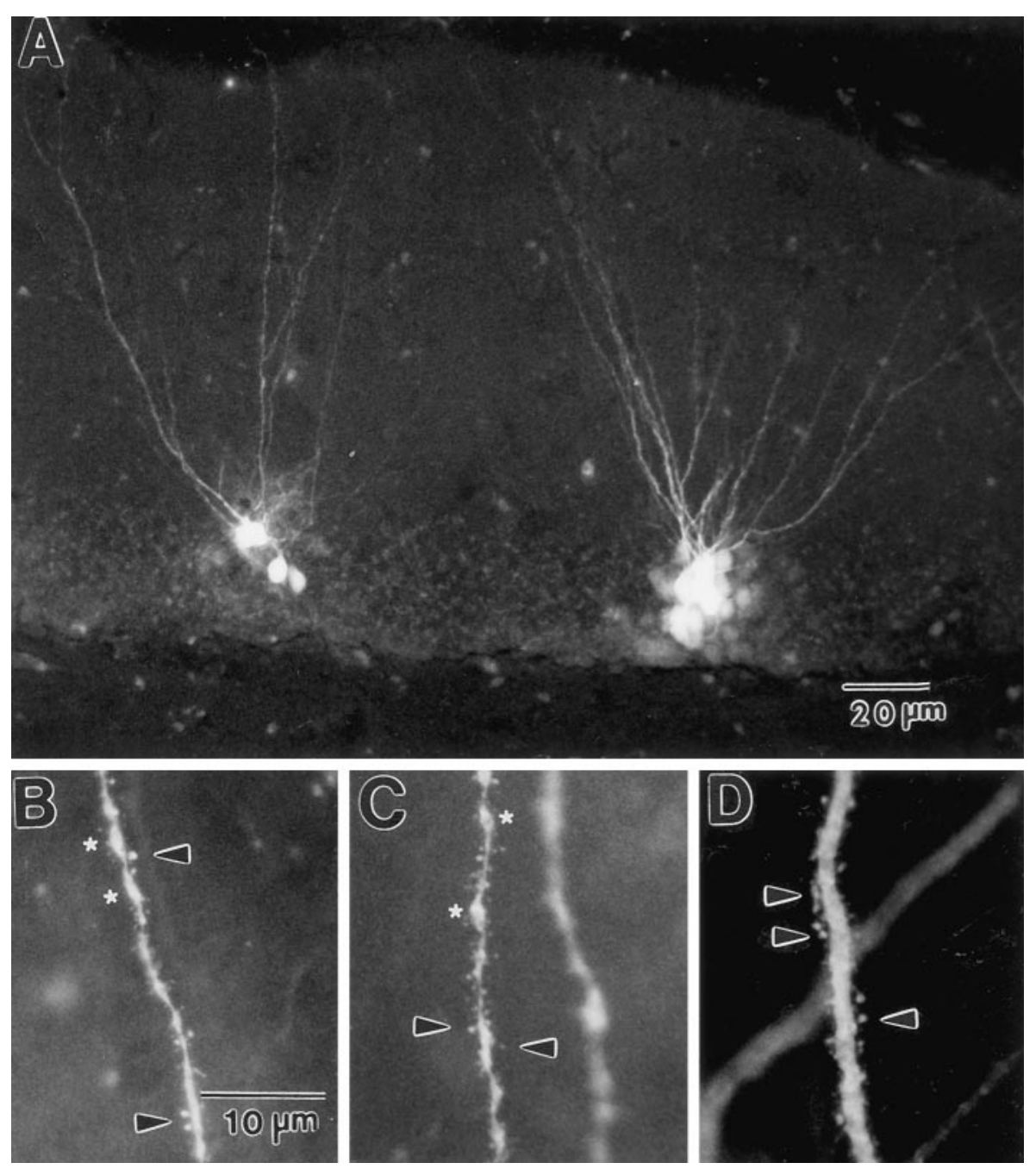

Figure 1. Photomicrographs of dentate granule cells from 16-month-old females filled with Lucifer yellow. $A$, Low magnification showing completeness of neuronal filling. Note that dendrites are filled to the boundary of the hippocampal fissure. $B, C$, High-magnification photomicrographs of proximal dendrites showing the level of detail observable by the intracellular filling at approximately the same level of the dendritic tree. Qualitative observation suggests that spine density under EB deprivation $(B)$ or long-term replacement $(C)$ is different from under short-term replacement $(D)$. Arrows point to dendritic spines; asterisks mark varicosities. Scale bar in $B$ also applies to $C, D$. a short-term pulse of estradiol. In males, as comparison groups, we gonadectomized and either left them in an androgen/ estrogen-deprived state or gave short-term estradiol replacement. Dendritic morphology was studied by making intracellular dye injections in fixed brain slices (Einstein, 1988).

\section{MATERIALS AND METHODS}

Twenty-five ovariectomized female and 14 gonadectomized male Charles River Sprague Dawley CD strain rats were used for this study. Rats were housed in same-sex pairs in clear plastic cages and were given food and water ad libitum. They were kept on a $12 \mathrm{hr}$ light/dark cycle with lights on at 7:30 A.M. All rats killed at 16-20 months of age were gonadectomized at 2 months of age, implanted with SILASTIC capsules filled with estradiol benzoate (EB) or oil, and behaviorally trained in an appetitively motivated learning paradigm at 3 months and again at 14 months of age (Williams, 1996).

Animal surgery. Ovariectomies were performed on all the female, and castrations were performed on all the male rats. They were anesthetized with a mixture of xylazine $(5 \mathrm{mg} / \mathrm{kg})$ and ketamine hydrochloride (45 $\mathrm{mg} / \mathrm{kg}$ ). During the same surgery, different groups of the females were implanted subcutaneously with the following doses of EB administered via SILASTIC capsule: (1) no estradiol, one $10 \mathrm{~mm}$ empty capsule $(n=$ 8); (2) low estradiol, one $15 \mathrm{~mm}$ capsule filled with a solution of $200 \mu \mathrm{g}$ of $\mathrm{EB} / \mathrm{ml}$ of sesame oil $(n=8)$; and (3) high estradiol, five $10 \mathrm{~mm}$ capsules filled with a solution of $200 \mu \mathrm{g}$ of $\mathrm{EB} / \mathrm{ml}$ of sesame oil $(n=4)$. The capsules were constructed using SILASTIC medical grade tubing (inner diameter of $0.147 \mathrm{~cm}$, outer diameter of $0.196 \mathrm{~cm}$ ), SILASTIC adhesive (Dow Corning Corporation, Midland, MI), and round toothpicks. The tubing was cut into 14 and $19 \mathrm{~mm}$ sections, and the ends were plugged with $2 \mathrm{~mm}$ of toothpick and an adhesive seal. None of the males received EB implants. Estradiol levels were checked monthly (blood was taken from the tail vein under $\mathrm{CO}_{2}$ anesthetic), and implants were replaced every 3-4 months as necessary to maintain serum estradiol levels. Median serum estradiol levels for long-term replacement were as follows: no estradiol, $<20 \mathrm{pg} / \mathrm{ml}$; low estradiol, $27.7 \mathrm{pg} / \mathrm{ml}$; and high estradiol, $42.95 \mathrm{pg} / \mathrm{ml}$.

At 16-20 months of age, four of the females with no estradiol replacement, four of the females with low estradiol replacement, and three of the males with no estradiol replacement were injected with $10 \mu \mathrm{g}$ of EB/0.1 $\mathrm{ml}$ of sesame oil at 48 and $24 \mathrm{hr}$ before being killed. At the same time points, matched groups of female and male rats were injected with an oil vehicle before being killed.

Another group of five female rats was ovariectomized, and eight male rats were gonadectomized at 4.5 months of age and killed 3 weeks later. Forty-eight and $24 \mathrm{hr}$ before being killed, three females and four males were injected with $10 \mu \mathrm{g}$ of $\mathrm{EB} / 0.1 \mathrm{ml}$ of sesame oil, and, at the same time, two females and four males were injected with an oil vehicle.

Preparation of tissue. All animals were killed by decapitation. The brains were removed immediately, cut in half along the midsagittal plane, and fixed in $4 \%$ paraformaldehyde in $0.1 \mathrm{M}$ PBS for $3 \mathrm{hr}$ at room temperature. After $3 \mathrm{hr}$, the left hemisphere was removed from fixative and rinsed in $0.1 \mathrm{M}$ PBS. Using a vibratome, sagittal sections of $300 \mu \mathrm{m}$ thickness were cut through the entire left hemisphere, collected in series in $0.1 \mathrm{M}$ PBS, and stored in the refrigerator in preparation for intracellular injection with Lucifer yellow.

Intracellular injections. Granule cells of the dentate gyrus were injected intracellularly with Lucifer yellow as described previously (Einstein, 1988). Cell filling was performed under visual control using epifluorescence. In all cases, at least three slices through the dentate gyrus were 


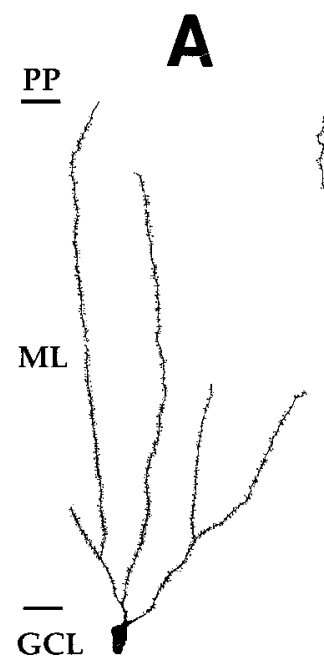

No EB

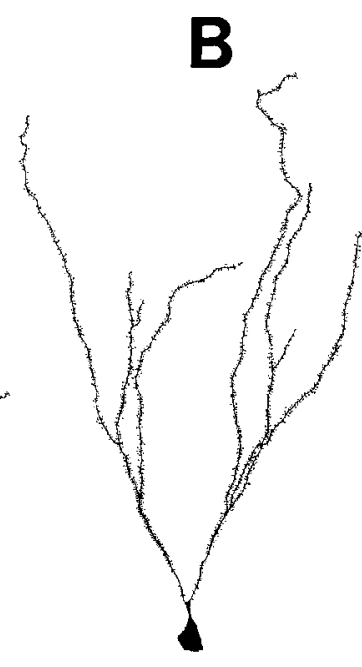

Low EB

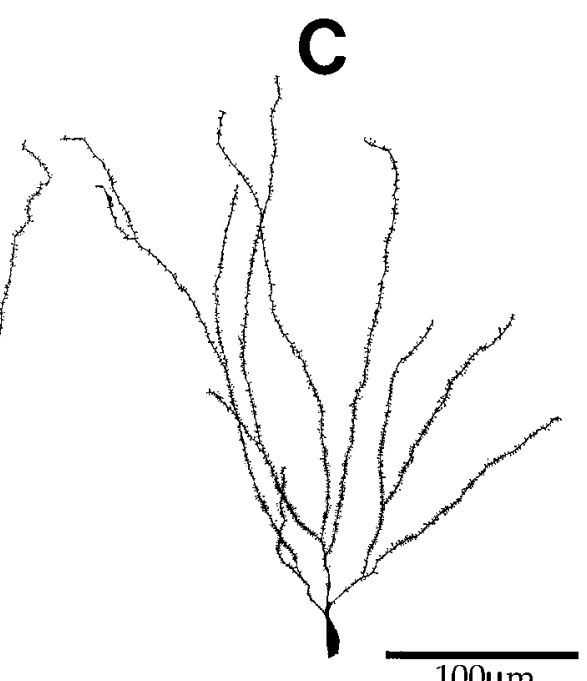

High EB

Figure 2. Camera lucida drawings and histogram demonstrating the relatively spine-poor state of 16- to 20-month-old female dentate granule cells and lack of observable difference in spine density between those with long-term estrogen deprivation and long-term estradiol replacement. $A$, Long-term deprivation. $B$, Long-term low-dose estradiol replacement. $C$, Long-term high-dose estradiol replacement. $D$, Histogram of spine density under each condition. Scale bar in $\mathrm{C}$ also applies to $A$ and $B$. $E B$, Estradiol benzoate; $G C L$, granule cell layer; $M L$, molecular layer; $P P$, perforant pathway. Note that there is one boundary for the perforant pathway marked for all the drawn neurons, although the molecular layer varies in width across its full extent. This abbreviation for purposes of visual clarity makes some dendritic trees appear to not branch the full extent of the molecular layer. However, all illustrated neurons have branches that filled to the perforant pathway unless they are obviously truncated by the plane of section of the slice. This holds true for all figures that follow, as well. $n=4$ for all conditions.
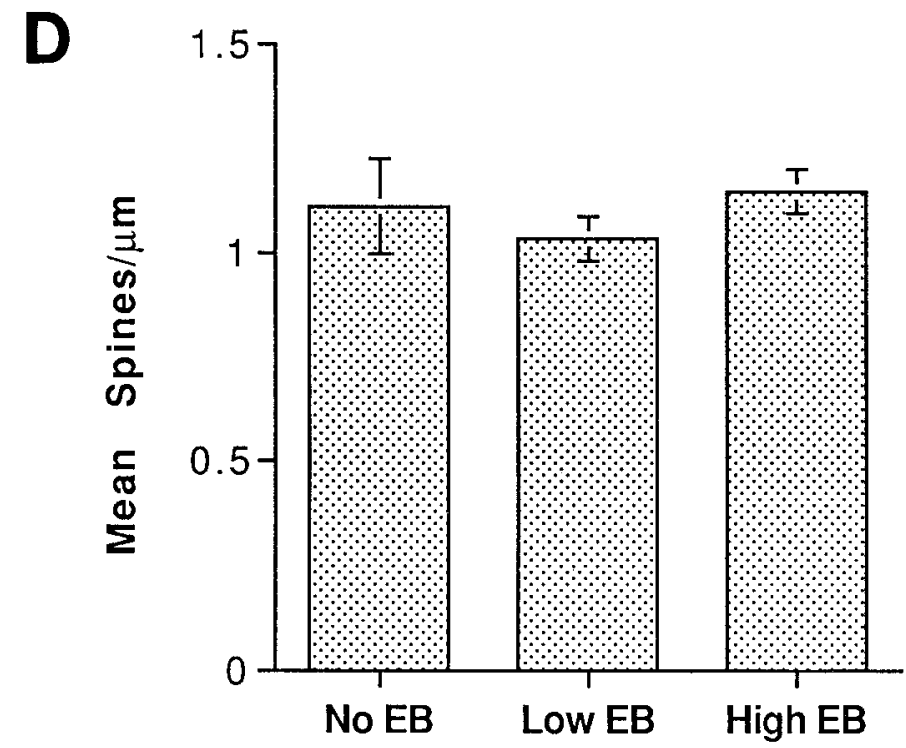

injected per animal, with $\sim 10-15$ granule cells injected per slice. To minimize any difficulties in interpreting morphological changes, slices from the dorsal hippocampus were used consistently (Buterbaugh and Hudson, 1991). To minimize differences in the dendritic field size and branching patterns of the dentate granule cells caused by position within the cell layer, as well as the possibility of injecting interneurons, granule cells located in the outer one-third of the granule cell layer were also chosen consistently (Green and Juraska, 1985; Claiborne et al., 1990; Soriano and Frotscher, 1993). Neurons in both the dorsal and ventral blades of the dentate were filled in approximately equal numbers and were analyzed separately, as well as together.

Data analysis. After injection, sections were rinsed in $0.1 \mathrm{M}$ PBS and post-fixed overnight in $10 \%$ formalin solution in $0.1 \mathrm{~m}$ PBS. Using a $4 \times$ objective and a drawing tube, the distribution of injected neurons on each slice was plotted, the number of neurons injected was counted, and the quality of intracellular filling was assessed. The tissue was placed in a solution of $25 \%$ sucrose in $0.1 \mathrm{M}$ PBS for cryoprotection and resectioned at $60 \mu \mathrm{m}$ on a freezing microtome. Sections were collected serially, mounted on gelatin-coated slides, air dried, and coverslipped with Krystalon (Diagnostic Systems, Webster, TX).

To ensure objectivity in our analysis, rats were killed, and brains were numbered by one of the coauthors; cell injections, drawing, and quantification of morphology was done by another. In addition, the drawings and data analysis were performed several months after the intracellular injections. In this way, all quantification of morphology was performed by experimenters who were blind to hormone condition.

Approximately 50 granule cells were filled intracellularly per rat. The criteria for choosing neurons to analyze in detail were as follows: (1) complete filling of dendritic tree out to the hippocampal fissure; (2) brightness or complete penetration of Lucifer yellow into dendrites and spines, as assessed at $160 \times$; and (3) soma located in the outer one-third of the granule cell layer. By these criteria, many neurons were well filled; however, only four of the best filled neurons from each blade were drawn and analyzed per rat. If neurons branched into several $60 \mu \mathrm{m}$ sections, their cell body and processes in each $60 \mu \mathrm{m}$ section were drawn and reconstructed for analysis. One aged female with no estradiol replacement and one young female with short-term estradiol replacement had no filled neurons that met our criteria for analysis; therefore, these animals were excluded. We measured dendritic length and counted the total number of varicosities and spines. Varicosities were identified as small oval swellings, integral to the dendrite. Spines were identified as smaller rounded protuberances, either extending from the dendrite via a thin shaft or lying close to or just slightly above the plane of focus of the dendrite. Both the density of varicosities and spines (number per micrometer) were calculated but kept separate so that the final spine count included no varicosities. An ANOVA (using the number of animals in each treatment group as the $n$ value) was used to assess the effects of aging and estradiol exposure on various features of neuronal morphol- 

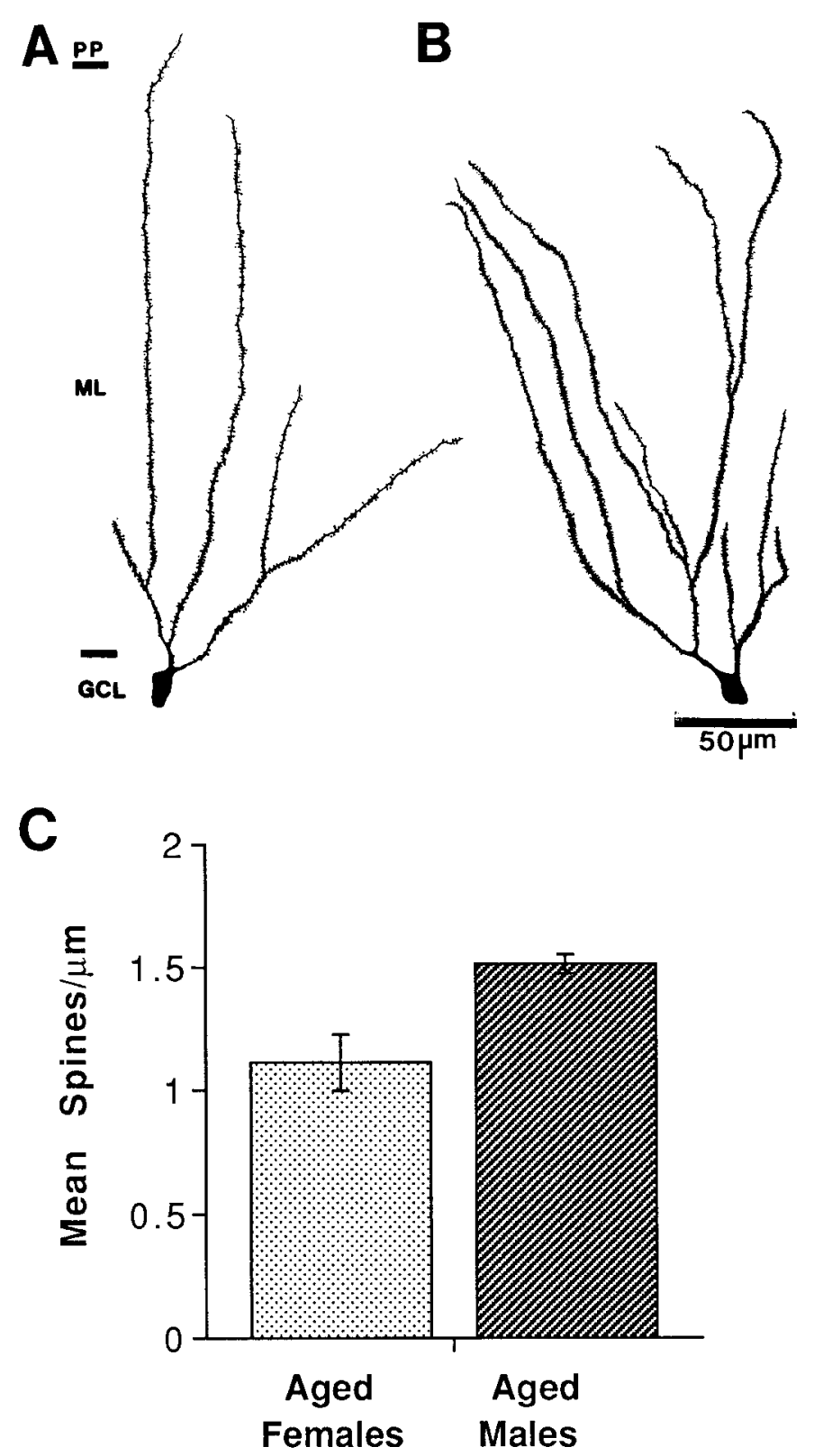

Figure 3. Camera lucida drawings and histogram showing an observable spine density in 16- to 20 -month-old female and male dentate granule cells with long-term estrogen deprivation. $A$, Female dentate granule cell. $B$, Male dentate granule cell. $C$, Histogram of spine density for females and males. $n=4$ for all conditions.

ogy. Dendritic length was not compared across treatment groups because dye injections in fixed slices occasionally yield truncated dendritic trees because of either sectioning or lack of diffusion of the dye. Therefore, this parameter was beyond the scope of the method.

\section{RESULTS}

Over 1000 dentate granule cells in females and males were filled intracellularly. Injection of granule cells with Lucifer yellow produced cell bodies and dendrites that were bright green or yellow in color, with crisp edges and spines that were well filled (Fig. $1 A-D)$. Because of the extremely small size of the cell bodies of granule cells $(8-10 \mu \mathrm{m}$ in diameter), multiple cells were occasionally filled at one injection site. However, it was still possible under high magnification to identify dendrites as belonging to a single cell body. Lucifer yellow filling was complete enough to reveal qualitative differences in spine density and morphology (Fig. $1 B-D$ ). In some animals, the dendrites carried irregular swellings resembling varicosities (Fig. $1 B, C$ ).

\section{Morphology of granule cells in aged rats in reproductive senescence}

To determine the morphology of dentate granule cells of female rats under various conditions of reproductive senescence, we studied filled neurons from aging females that had been deprived of gonadal steroids for $>12$ months (mimicking human menopause) and those replaced with low and high concentrations of estradiol (mimicking rat persistent diestrous and constant estrous, respectively). Qualitative inspection of neurons from all three conditions revealed dendritic trees with a paucity of spines (Fig. $2 A-C)$. Subsequent quantification of spine density revealed no significant difference in spine density between females that had been estrogen-deprived and those that had received either form of long-term replacement (Fig. 2D).

To determine whether there was a sex difference in the effects of aging with long-term steroid deprivation, we also examined filled dentate granule cells from aging males deprived of gonadal steroids for $>12$ months. In contrast to the females, qualitative inspection of neurons from aged males revealed dendritic trees with no paucity of spines (Fig. 3). An ANOVA with sex as the independent variable revealed a significant sex difference in spine density of granule cells of long-term gonadectomized rats $\left(F_{(1,4)}\right.$ $=11.04 ; p<0.05)$.

\section{Morphology of granule cells in aged rats with short- term replacement of estradiol}

To determine whether dentate granule cells from aged rats might be responsive to a pulse of estradiol, we compared the morphology of dentate granule cells from aged, long-term gonadectomized male and female rats that received short-term estradiol replacement with rats that received control oil injections. Qualitative inspection of neurons from aged females revealed that rats with short-term estradiol replacement had granule cells with full spiny dendritic trees compared with those with no replacement (Fig. $4 A, B, E$ ). In contrast, qualitative inspection of granule cells of male rats revealed less spiny dendritic trees in the estradiolreplaced males compared with those with no replacement (Fig. $4 C, D)$. A two-way ANOVA with sex and short-term EB treatment as factors revealed no significant effects of either treatment or sex but did reveal a significant interaction between sex and EB treatment $\left(F_{(1,9)}=11.333 ; p<0.005\right)$. Short-term estradiol replacement also increased the spine density of neurons from females that had received long-term replacement of low doses of EB. Qualitative inspection of these granule cells revealed fully branching dendritic trees with many spines (Fig. 5C,D). Quantitative analysis of spine density revealed that short-term EB replacement increased dendritic spine density regardless of previous long-term EB exposure (Fig. 5E). A two-way ANOVA with short-term and long-term EB replacement as factors revealed no significant effect of long-term treatment alone and no interaction between long-term and short-term EB replacement. It did reveal a significant effect of short-term EB replacement $\left(F_{(1,11)}=\right.$ 17.268; $p<0.005)$.

When we examined spine densities of granule cells from the dorsal and ventral blades of the dentate gyrus separately, we found that EB replacement appeared to increase spine density in females mainly in the neurons of the dorsal blade (Fig. 6). A 


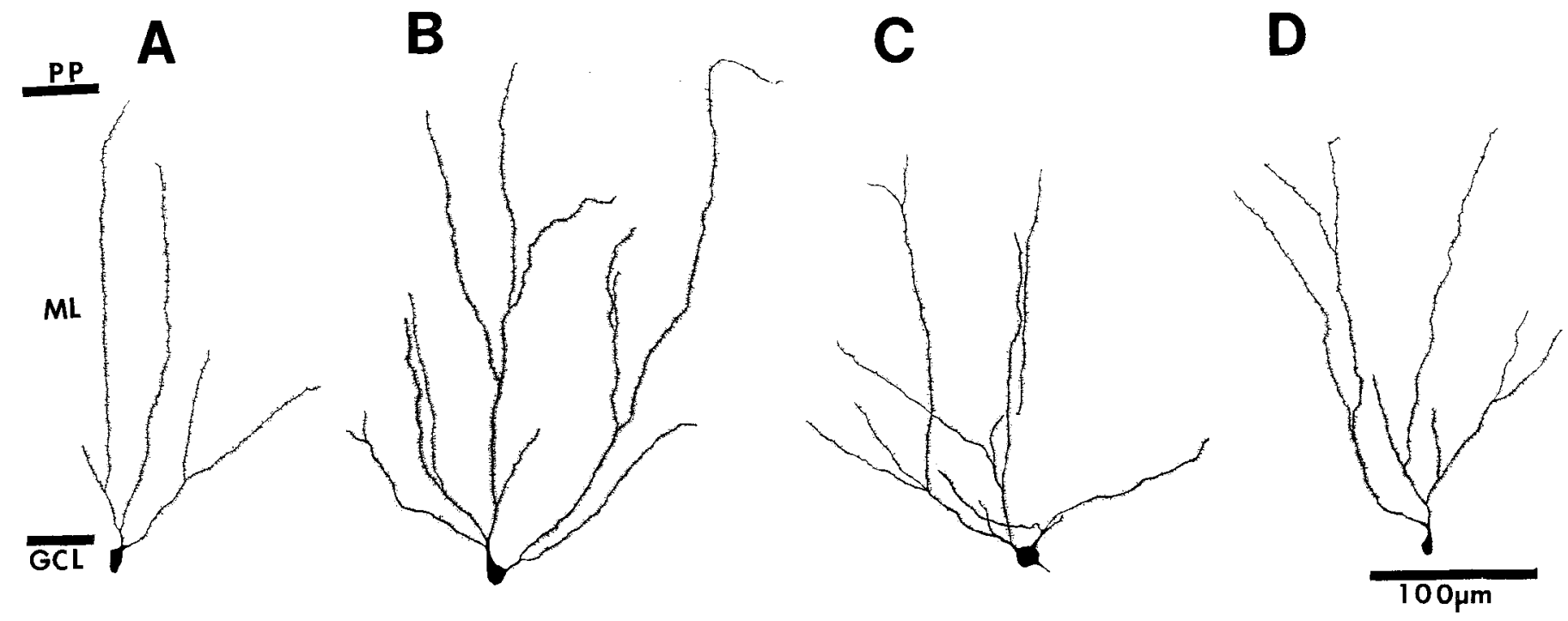

E

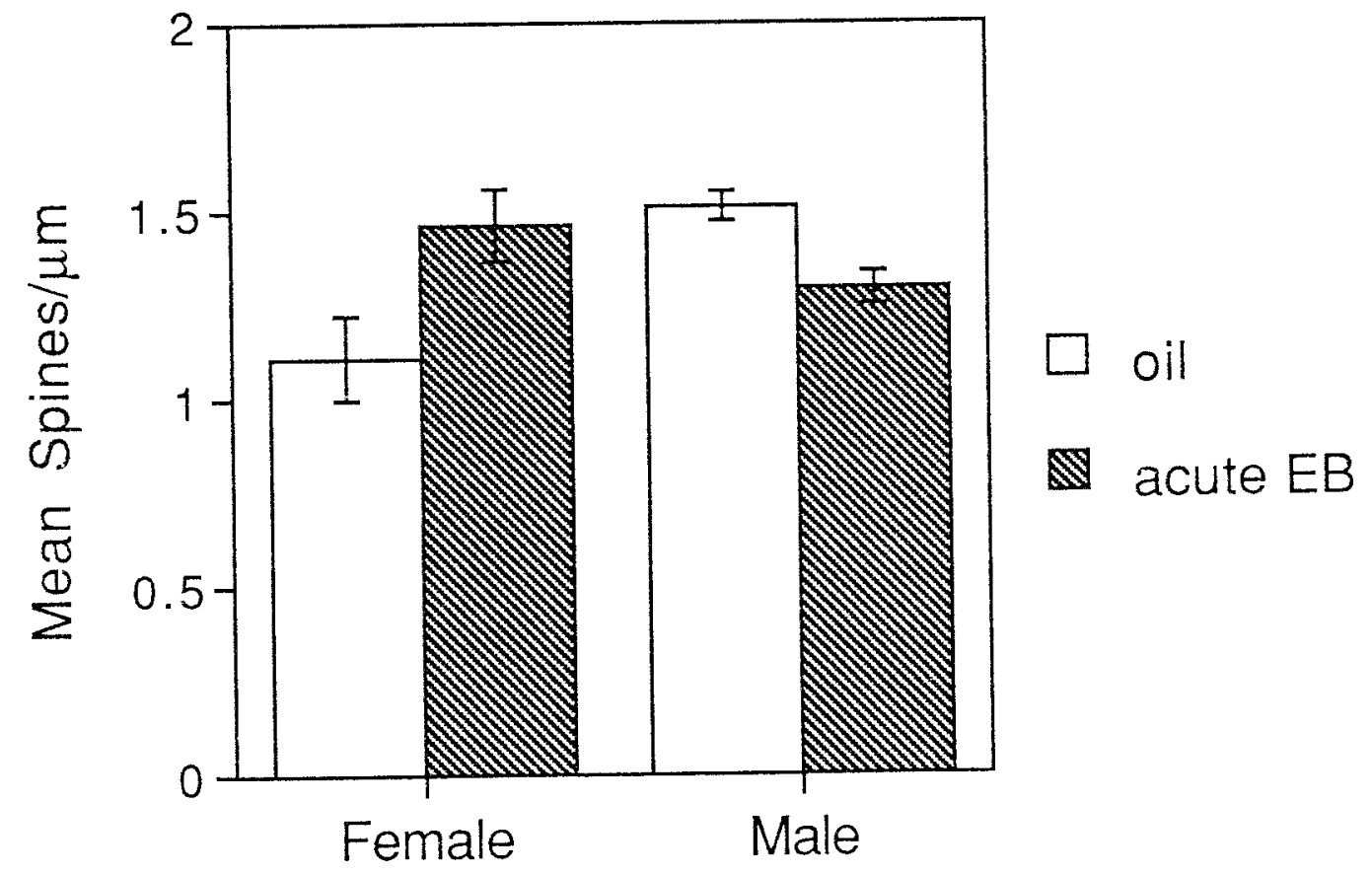

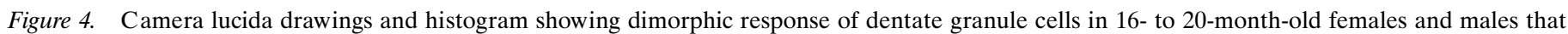

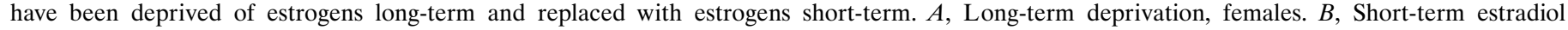

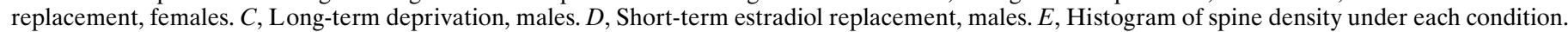

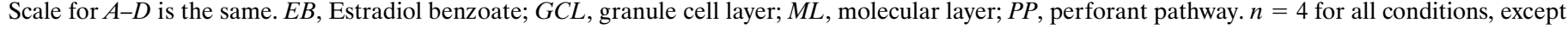
short-term replacement for the males for which $n=3$.

two-way ANOVA on spine densities of dorsal blade cells only also revealed no significant effect of treatment or sex but did reveal a significant sex by EB treatment interaction $\left(F_{(1,9)}=7.515 ; p<\right.$ $0.05)$. The same analysis run on ventral blade neurons revealed no significant main effects or interactions.

Varicosities were counted separately from spines; age nor treatment nor sex influenced the number or density of varicosities significantly. There were also no significant correlations between varicosities and spine density across conditions.

\section{Interaction of aging and short-term replacement of estradiol}

To determine whether there was an interaction between aging and short-term estrogen replacement, we compared the spine density of dentate granule cells in young female and male rats gonadectomized 3 weeks before being killed with granule cells from aged females and males gonadectomized 14-28 months before being killed. We found that dentate granule cells from young females deprived of gonadal steroids for only a few weeks 

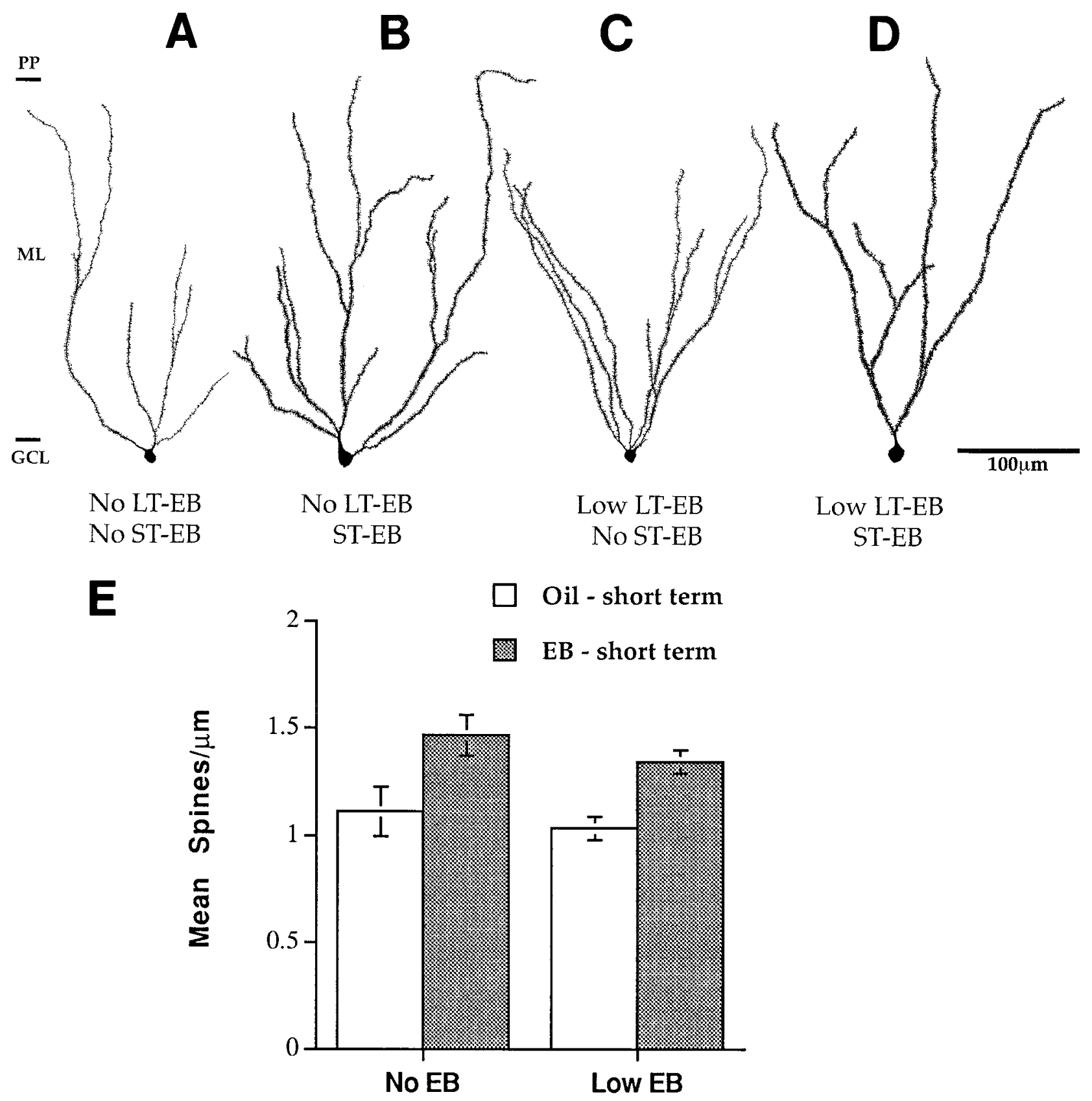

Figure 5. Camera lucida drawings and histogram showing that after ovariectomy at 2 months of age, dentate granule cells in 16- to 20-month-old females respond to short-term replacement of estrogens whether they have been deprived of estrogens long-term or had low levels of long-term EB replacement. $A$, Estrogen-deprived state. $B$, Short-term EB replacement after estrogen deprivation. $C$, Long-term low-estradiol replacement. $D$, Short-term estrogen replacement after long-term low-estradiol replacement. Note how spine density increases after short-term replacement regardless of whether the neurons are deprived or have long-term low-dose replacement. $E$, Histogram of spine density. Scale for $A-C$ is the same. $S T$, Short-term; $L T$, long-term; $E B$, estradiol benzoate. $n=4$ for all conditions.

were noticeably spinier than then those from aged females that had suffered long-term deprivation (Fig. $7 A, C$ ). In fact, shortterm EB replacement appeared to return dendritic spine density in aged ovariectomized females to that of the younger ovariectomized females (Fig. $7 A, D$ ). In contrast to the aged females, the spine density of dentate granule cells in young females was not altered by ovariectomy or EB replacement (Fig. $7 A-D$ ). Quantification supported these qualitative observations; a two-way ANOVA with age and EB replacement as factors revealed no significant effect of age or short-term EB replacement on granule cell spine density. However, there was a significant interaction between age and short-term EB replacement $\left(F_{(1,8)}=7.109 ; p<\right.$ $0.05)$ (Fig. 7E).

In contrast, in males, dentate granule cells from young rats deprived of androgens for only a few weeks were not noticeably different from granule cells of aged rats that had suffered longterm androgen deprivation (Fig. 8). Visual inspection revealed that short-term EB replacement tended to decrease spine density 

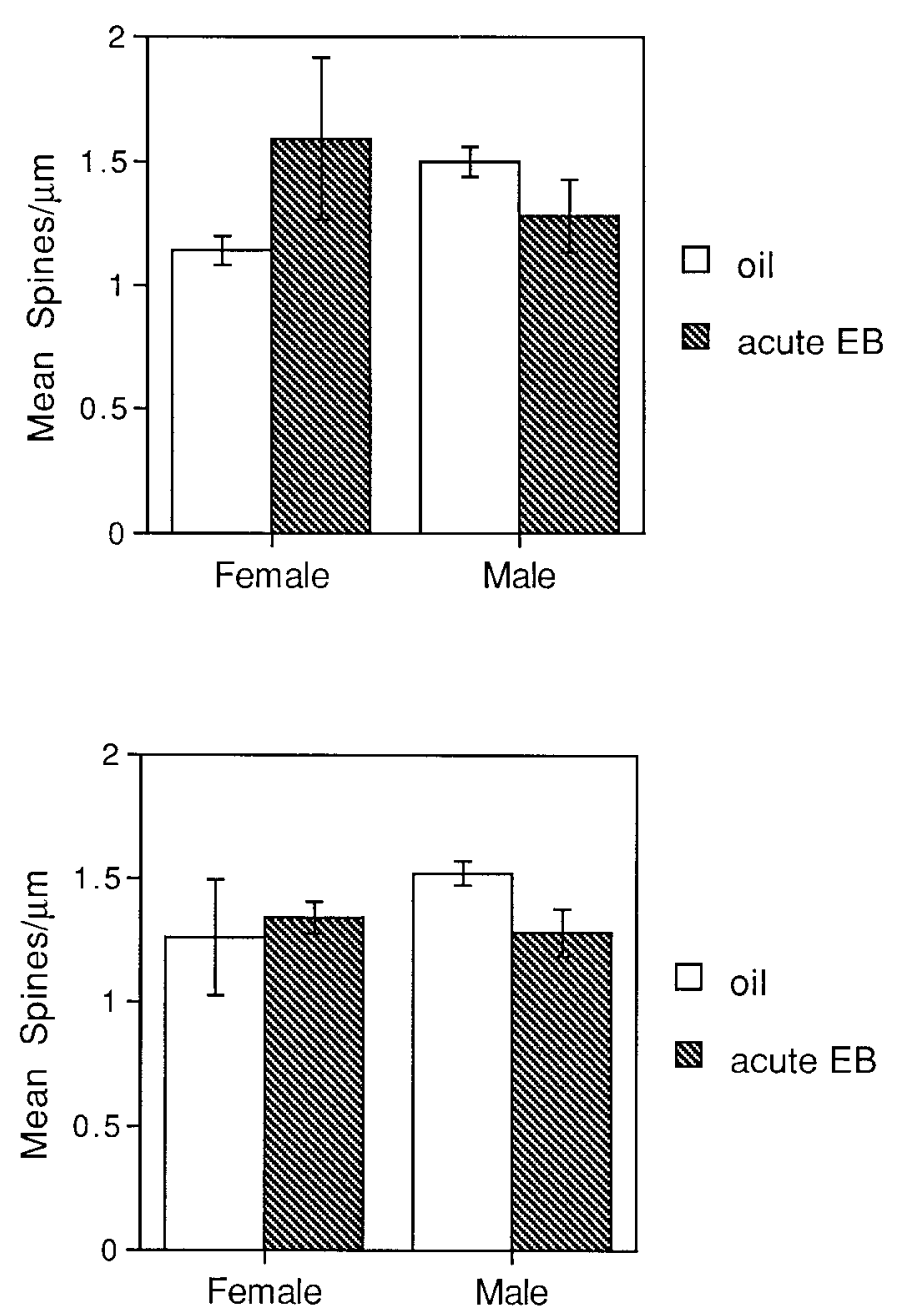

Figure 6. Histograms of spine density of dentate granule cells of 16month-old females and males in dorsal and ventral blades with long-term estrogen deprivation and short-term replacement. $A$, Spine density of granule cells in the dorsal blade. $B$, Spine density of granule cells in the ventral blade. Note that whereas the effect in the females is carried primarily by the dorsal blade, the effect in the males is carried by both the dorsal and ventral blades. $n=4$ for all conditions, except short-term replacement for the males for which $n=3$.

slightly in both young and aged rats, but the effect of EB replacement was significant only in the aged male rats $\left(F_{(1,4)}=14.06 ; p<\right.$ $0.05)$.

\section{DISCUSSION}

We investigated the effects of estrogen deprivation and replacement on dentate granule cells in aged long-term gonadectomized female and male rats. This work emerges from the important observation of Woolley and McEwen (1992) that the spine density of apical dendrites of CA1 pyramidal neurons changes over the $4 \mathrm{~d}$ period of the rat estrous cycle. Our new approach was to focus on the effects of estrogen deprivation and replacement on the aging brain, to examine a different neuronal population, and to compare responses of females and males. We found the following. (1) Aged females deprived of gonadal steroids long-term have a paucity of dendritic spines on hippocampal granule cells compared with young females deprived for the short-term; however, aged males deprived of gonadal steroids long-term show no decrease in dendritic spines compared with young males deprived for the short-term. (2) No difference in spine density exists between females that suffered long-term deprivation and those exposed to long-term replacement of both high and low doses of EB. (3) Short-term estradiol replacement to aged female rats increases spine density of hippocampal granule cells to levels observed in young adults and decreases spine density in aged males.

We used intracellular dye injections that revealed dendritic morphology in as much detail as Golgi methods (Gould et al., 1990a,b; Woolley et al., 1990; Woolley and McEwen, 1992). Others have also found dye filling to be a method that allows complete documentation of changes in spine density in response to estradiol administration (Woolley et al., 1997). Although our spine densities are in the range of those reported in other studies (Hama et al., 1989; Trommald et al., 1995), absolute numbers of dendritic spines will always remain in question because sex and treatment of the animals differ between studies. For technical reasons alone, spine numbers vary from study to study depending on whether or not correction values are used (Feldman and Peters, 1979) and which morphological method is used. In this study, all the drawing and spine counts were performed by one person (P.M.), ensuring consistent intrastudy values and allowing us to demonstrate changes in relative densities.

We demonstrate that, in aged females that have been ovariectomized for many months, acute estradiol administration quickly (in $<48 \mathrm{hr}$ ) increases granule cell spine density. This is surprising because, in young females, dentate granule cells (in contrast to CA1 pyramidal neurons) do not respond rapidly to estradiol administration or to the natural fluctuation of hormones during the estrous cycle (Gould et al., 1990b; Woolley and McEwen, 1992, 1993, 1994; present report). These results demonstrate that the aged hippocampus is still rapidly responsive to acute changes in the hormonal milieu. Whether it is aging and/or estrogen deprivation that increases estradiol responsivity in this neuronal population remains to be determined. However, we have found that after ovariectomy of 5-month-old rats, spine density of granule cells declines very slowly over months, not days, suggesting that in young females granule cell spine density is not maintained by circulating estradiol (C. Cullen, C. Williams, and G. Einstein, unpublished observations).

Our finding that chronic long-term estradiol replacement in females results in the same decrease in dendritic spine density as complete estrogen deprivation suggests that responsivity of neurons to estrogen requires a cyclical or pulsatile exposure. This is an intriguing finding because it suggests that the common feature of hormonal aging in rats and humans is that the aging female is no longer exposed to cyclical changes in ovarian secretions. $\mathrm{Hu}$ man females experience many years of estrogen deprivation after menopause, whereas rats undergo a stage of constant estrus when estrogen levels are constant but high and then persistent diestrus when estrogen levels are constant and low (Lefevre and McClintock, 1988). Given our results, it is possible that if aging female rats were to continue to cycle regularly or to receive cyclical estradiol replacement, spine density of the granule cells would be maintained into old age. In fact, our finding that short-term estradiol replacement increases spine density in dentate granule cells of long-term ovariectomized aged female rats demonstrates that these neurons are still responsive to estrogen, but their responsiveness depends on the pattern of estrogen exposure. Whether dentate granule cells of aged females would undergo remodeling under conditions that mimic ovarian hormone cycling remains to be determined.

The pattern of response of dentate granule cell spines to 


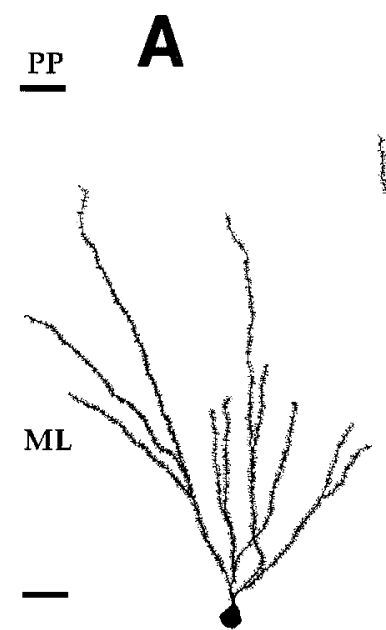

GCL

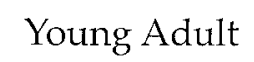

No ST-EB

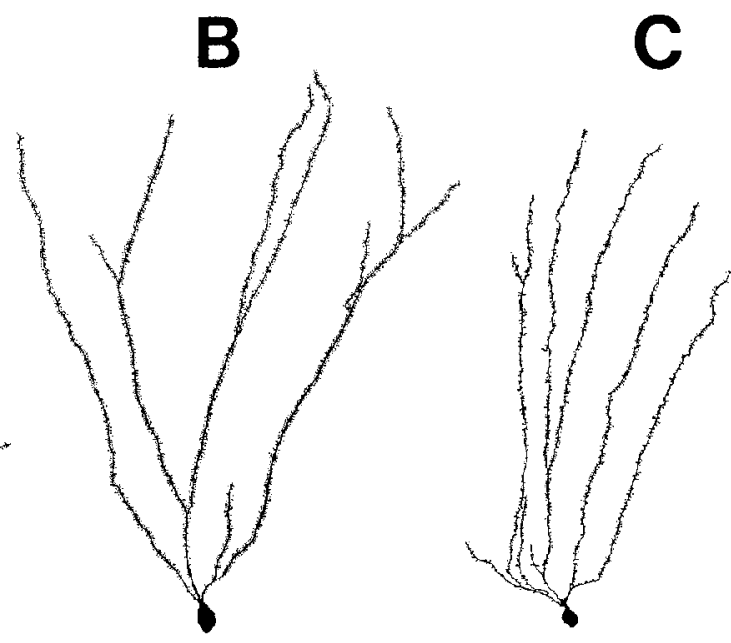

Young Adult
Aged Adult

No ST-EB
D

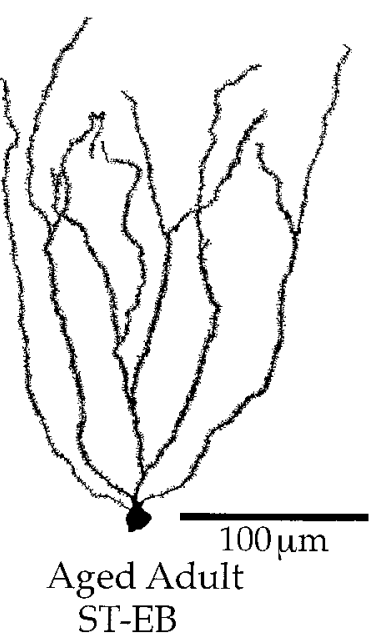

ST-EB

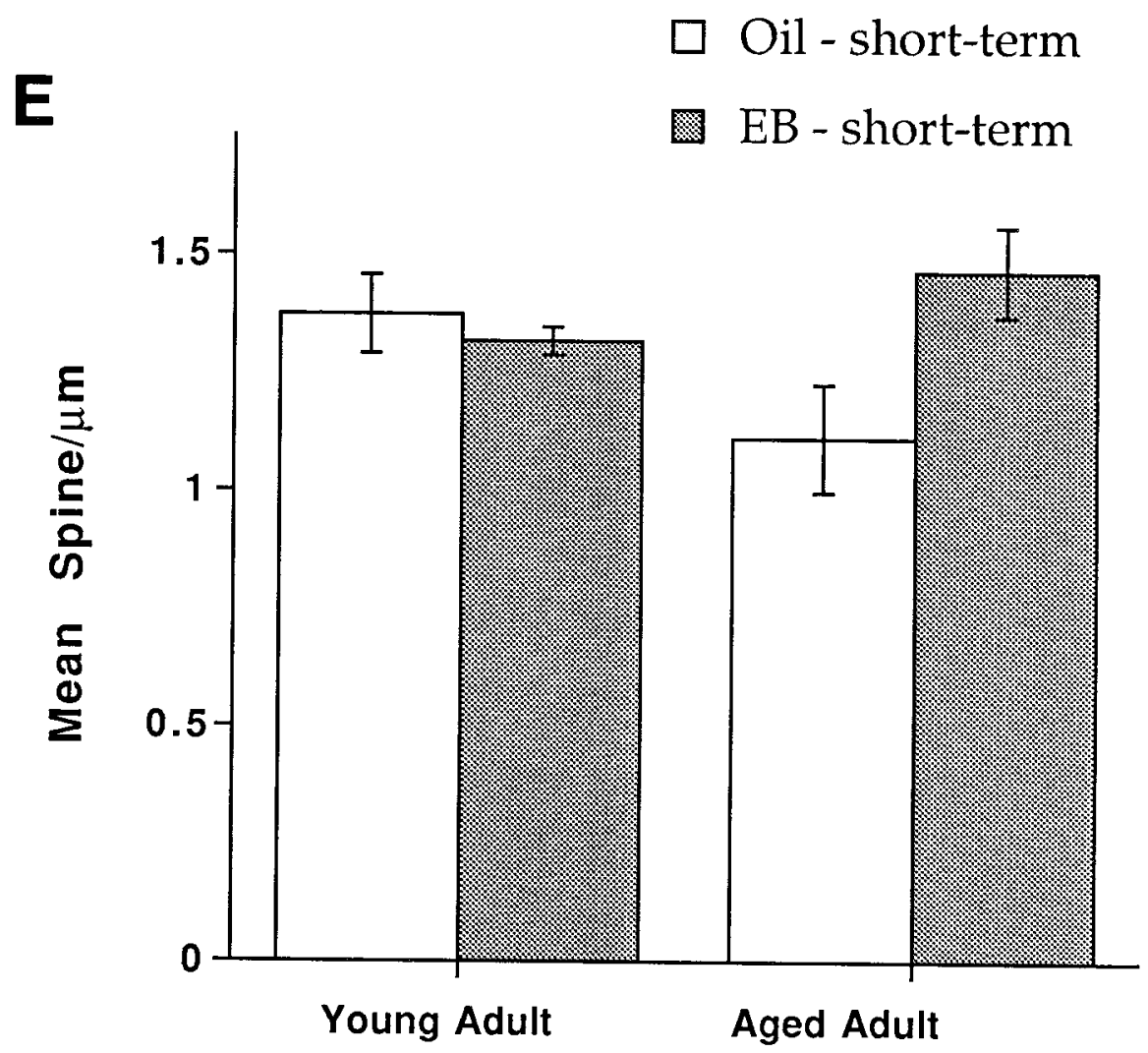

Figure 7. Camera lucida drawings and histogram showing that dentate granule cells in females ovariectomized at 4.5 months do not respond to short-term EB replacement at 5 months of age, whereas 16- to 20 -month-old females ovariectomized at 2.5 months do respond to short-term EB replacement. $A$, Estrogen-deprived young adult. Note the full spiny dendritic tree. $B$, Young adult with short-term estradiol replacement. Note that there is relatively little change in spine density compared with $A$. $C$, Aged adult, estrogen-deprived. Note the paucity of dendritic spines. $D$, Aged adult, short-term EB replacement. Note the dramatic increase in spine density compared with $C$. $E$, Histogram of spine densities. Scale bar in $D$ also applies to $A-C$. ST, Short term; $L T$, long-term; $E B$, estradiol benzoate. $n=4$ for all conditions, except short-term replacement for the females for which $n=3$.

gonadectomy and estrogen replacement is quite different in aged male rats. Aged males do not show an age-related decline in granule cell spines after long-term gondectomy, and in response to short-term estradiol replacement spines are lost, suggesting that females and males age differently on the neuronal level. This sexually dimorphic response may be programmed by developmental history. Neurons in the ventromedial hypothalamus also show this same type of dimorphism; replacing estradiol in gonadectomized females increases spine density, whereas it decreases spine density in males (Lewis et al., 1995). Thus, depending on 


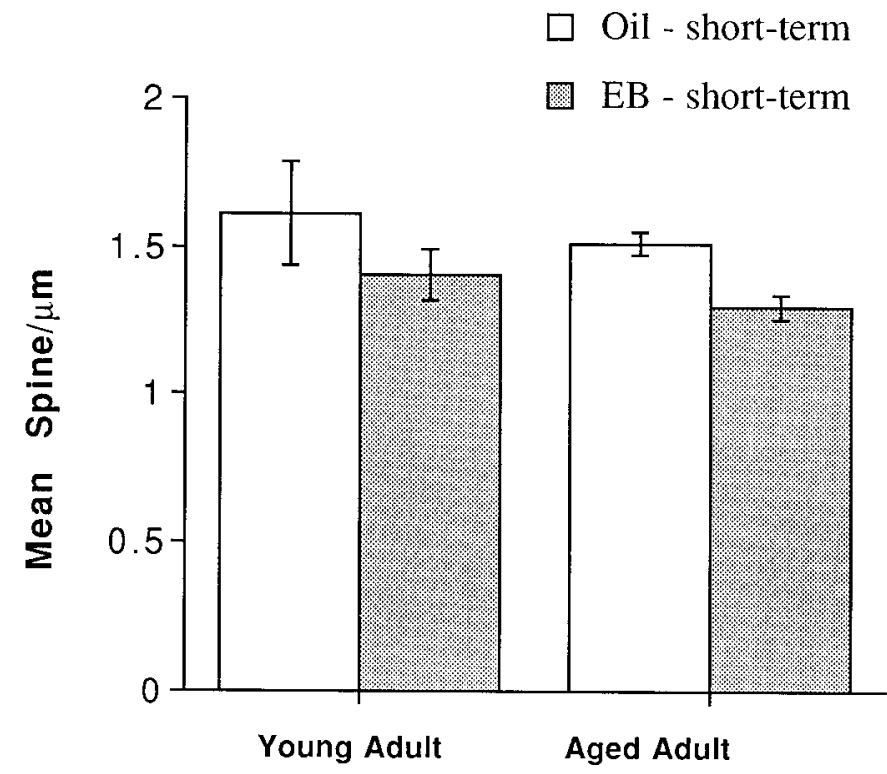

Figure 8. Histogram showing that dentate granule cells in males gonadectomized at 2.5 months show a decrease in spine density at both 5 months and 16-20 months after short-term EB replacement. $E B$, Estradiol benzoate. $n=4$ for all conditions, except short-term replacement in the older males for which $n=3$.

sex, neurons in different brain regions may have similar responses to estradiol replacement, reflecting the difference in developmental plan between female and male.

What is the mechanism by which a previously unresponsive neuronal type becomes responsive? Although estrogens can act to alter gene transcription (McEwen et al., 1978), it is unlikely that this is the case in the present study because in the hippocampus, both $\alpha$ - and $\beta$-estrogen receptors have been identified on interneurons and glial cells and not on dentate granule cells (Rainbow et al., 1982; Loy et al., 1988; Pelletier et al., 1988; Weiland et al., 1996; Kuiper et al., 1997; Li et al., 1997). Estradiol might act directly on membranes, altering their properties to induce glutamate release, thus increasing intraneuronal calcium, stimulating NMDA receptors, leading to the addition of dendritic spines (Parpura et al., 1994; Woolley and McEwen, 1994; Klintsova et al., 1995). Estradiol might also affect dentate granule cells via astrocytes (Klintsova et al., 1995). The explanation we favor, however, is that estrogen may be acting indirectly on neurons projecting to dentate granule cells, such as entorhinal cortical or basal forebrain neurons that are known to have estrogen receptors (Pfaff and Keiner, 1973; Loy et al., 1988; Weiland et al., 1996). Such sensitivity to denervation and reinnervation would not be unusual for dentate granule cells and is reminiscent of their quick loss of spines because of loss of inputs during aging or disease (Nadler et al., 1973, 1977; White et al., 1979; Flood and Coleman, 1986; Flood, 1987; Einstein et al., 1994; Shetty and Turner, 1995). Our finding that the brunt of the effect is carried by neurons of the dorsal blade further supports the hypothesis that responsivity to estrogens is caused by denervationinnervation effects because granule cells in the dorsal and ventral blades have been shown to differ in both morphology (Claiborne et al., 1990) and inputs (Amaral and Witter, 1995).

The functional ramification of increased or decreased spine density is still an open question. It has been shown in male rodents that spine density and number of excitatory synapses correlate with the efficiency of learning spatial tasks (Moser et al., 1994). Direct correlation of changes in spine density with changes in synaptic density suggests that, at the very least, changes in spine density reflect changes in excitatory input (Westrum and Blackstad, 1962; Calverley and Jones, 1990; Jaslove, 1992; Woolley and McEwen, 1992); by the same token, decreases in spine density probably reflect a loss of excitatory inputs and thus a decrease in neuronal excitability. Exacerbation of spine loss by estrogen deprivation in normal aging suggests that the estrogendeficient state after human menopause is one of decreased excitatory synaptic input, which may contribute to cognitive decline in aging and Alzheimer's disease-affected women.

It also suggests that recently reported positive effects of hormone replacement therapy, such as the reversal of normal memory decline in elderly women (Henderson, 1994), the delay in the age of onset of Alzheimer's disease (Paganini-Hill and Henderson et al., 1994; Kawas et al., 1997), and the amelioration of cognitive decline in Alzheimer's disease (Fillit et al., 1986; Ohkura et al., 1994a,b; Birge, 1997), may be mediated through structural changes of hippocampal neurons. Our data suggest that administering estrogens in a cyclic manner in humans might strengthen neuronal connectivity, which might lead to cognitive enhancement. This newly discovered rapid plasticity in the female brain may have implications for the protection of neurons in Alzheimer's disease, as well as for our conception of the relative effects of aging on the female and male brain.

\section{REFERENCES}

Alliot J, Giry N (1991) Acquisition of a matching-to-sample task in young and middle-aged male and female rats. NeuroReport 2:101-104.

Amaral DG, Witter MP (1995) Hippocampal formation. In: The rat nervous system (Paxinos G, ed), pp 443-490. San Diego: Academic.

Birge SJ (1997) The role of estrogen in the treatment of Alzheimer's disease. Neurology 48:S36-S41.

Buterbaugh GG, Hudson GM (1991) Estradiol replacement to female rats facilitates dorsal hippocampal but not ventral hippocampal kindled seizure acquisition. Exp Neurol 111:55-64.

Calverley RK, Jones DG (1990) Contributions of dendritic spines and perforated synapses to synaptic plasticity. Brain Res Rev 15:215-249.

Chiarello C, Hoyer WJ (1988) Adult age differences in implicit and explicit memory: time course and encoding effects. Psychol Aging 3:358-366.

Claiborne BJ, Amaral DG, Cowan WM (1990) Quantitative threedimensional analysis of granule cell dendrites in the rat dentate gyrus. J Comp Neurol 302:206-219.

Einstein G (1988) Intracellular injections of Lucifer yellow into cortical neurons in lightly fixed sections and its application to human autopsy material. J Neurosci Methods 26:95-103.

Einstein G, Buranosky R, Crain BJ (1994) Dendritic pathology of granule cells in Alzheimer's disease is unrelated to neuritic plaques. J Neurosci 14:5077-5088.

Feldman ML, Peters A (1979) A technique for estimating total spine numbers on Golgi-impregnated dendrites. J Comp Neurol 188:527-542.

Fillit H, Weinreb H, Cholst I, Luine V, McEwen B, Amador R, Zabriskie J (1986) Observations in a preliminary open trial of estradiol therapy for senile dementia-Alzheimer's type. Psychoneuroendocrinology 11:337-345.

Flood DG, Coleman PD (1986) Failed compensatory dendritic growth as a pathophysiological process in Alzheimer's disease. Can J Neurol Sci 13:475-479.

Flood DG, Buell SJ, Horwitz GJ, Coleman PD (1987) Dendritic extent in human dentate gyrus granule cells in normal aging and senile dementia. Brain Res 402:205-216.

Frick KM, Baxter MG, Markowska AL, Olton DS, Price DL (1995) Age-related spatial reference and working memory deficits assessed in the water maze. Neurobiol Aging 16:149-160.

Garcia-Segura LM, Perez J, Jones E, Naftolin F (1991) Loss of sexual dimorphism in rat arcuate nucleus neuronal membranes with reproductive aging. Exp Neurol 112:125-128. 
Gould E, Allan MD, McEwen B (1990a) Dendritic spine density of adult hippocampal pyramidal cells is sensitive to thyroid hormone. Brain Res 525:327-329.

Gould E, Woolley CS, Frankfurt M, McEwen BS (1990b) Gonadal steroids regulate dendritic spine density in hippocampal pyramidal cells in adulthood. J Neurosci 10:1286-1291.

Green EJ, Juraska JM (1985) The dendritic morphology of hippocampal dentate granule cells varies with their position in the granule cell layer: a quantitative Golgi study. Exp Brain Res 59:582-586.

Hama K, Arii T, Kosaka T (1989) Three-dimensional morphometrical study of dendritic spines of the granule cell in the rat dentate gyrus with HVEM stereo images. J Electron Microsc Tech 12:80-87.

Henderson P, Williams CL, Einstein G (1996) Acute but not chronic administration of estradiol increases spine density of dentate granule cells in the aged rat. Soc Neurosci Abstr 2:1164.

Henderson VW (1997) The epidemiology of estrogen replacement therapy and Alzheimer's disease. Neurol 48:S27-S35.

Henderson VW, Paganini-Hill A, Emanuel CK, Dunn ME, Buckwalter JG (1994) Estrogen replacement therapy in older women. Arch Neurol 51:896-900.

Jaslove SW (1992) The integrative properties of spiny distal dendrites. Neuroscience 47:495-519.

Kadar T, Silbermann M, Brandeis R, Levy A (1990) Age-related structural changes in the rat hippocampus: correlation with working memory deficiency. Brain Res 512:113-120.

Kawas C, Resnick S, Morrison A, Brookmeyer R, Corrada M, Zonderman A, Bacal C, Lingle DL, Metter E (1997) A prospective study of estrogen replacement therapy and the risk of developing Alzheimer's disease: the Baltimore longitudinal study of aging. Neurology 48:1517-1521.

Kimura D (1995) Estrogen replacement therapy may protect against intellectual decline in postmenopausal women. Horm Behav 29:312-321.

Klintsova A, Levy WB, Desmond NL (1995) Astrocytic volume fluctuates in the hippocampal CA1 region across the estrous cycle. Brain Res 690:269-274.

Kuiper GG, Carlsson B, Grandien K, Enmark E, Haggblad J, Nilsson S, Gustafsson JA (1997) Comparison of the ligand binding specificity and transcript tissue distribution of estrogen receptors $\alpha$ and $\beta$. Endocrinology 138:863-870.

Lefevre J, McClintock MK (1988) Reproductive senescence in female rats: a longitudinal study of individual differences in estrous cycles and behavior. Biol Reprod 38:780-789.

Lewis C, McEwen BS, Frankfurt M (1995) Estrogen-induction of dendritic spines in ventromedial hypothalamus and hippocampus: effects of neonatal aromatase blockade and adult GDX. Dev Brain Res 87:91-95.

Li X, Schwartz PE, Rissman EF (1997) Distribution of estrogen receptor- $\beta$-ligand immunoreactivity in rat forebrain. Neuroendocrinology 66:63-67.

Loy R, Gerlach JL, McEwen BS (1988) Autoradiographic localization of estradiol-binding neurons in the rat hippocampal formation and entorhinal cortex. Dev Brain Res 39:245-251.

McEwen BS, Krey LC, Luine VN (1978) Steroid hormone action in the neuroendocrine system: when is the genome involved? Res Publ Assoc Res Nerv Ment Dis 56:255-268.

Moroi-Fetters S, Mervis RF, London ED, Ingram DK (1989) Dietary restriction suppresses area related changes in dendritic spines. Neurobiol Aging 10:317-322.

Moser MB, Trommald M, Andersen P (1994) An increase in dendritic spine density on hippocampal CA1 pyramidal cells following spatial learning in adult rats suggests the formation of new synapses. Proc Nat Acad Sci USA 91:12673-12675.

Nadler JV, Cotman CW, Lynch GS (1973) Altered distribution of choline acetyltransferase and acetylcholinesterase activities in the developing rat dentate gyrus following entorhinal lesion. Brain Res 63:215-220.

Nadler JV, Cotman CW, Paoletti C, Lynch GS (1977) Histochemical evidence of altered development of cholinergic fibers in the rat dentate gyrus following lesions. II. Effects of partial entorhinal and simultaneous multiple lesions. J Comp Neurol 171:589-604.

Nunzi MG, Milan F, Guidolin D, Toffano G (1987) Dendritic spine loss in hippocampus of aged rats. Effect of brain phosphatidylserine administration. Neurobiol Aging 8:501-510.

Ohkura T, Isse K, Akazawa K, Hamamoto M, Yaoi Y, Hagino N (1994a)
Evaluation of estrogen treatment in female patients with dementia of the Alzheimer type. Endocr J 41:361-371.

Ohkura T, Isse K, Akazawa K, Hamamoto M, Yaoi Y, Hagino N (1994b) Low-dose estrogen replacement therapy for Alzheimer's disease in women. Menopause 1:125-130.

O’Neal MF, Means LW, Poole MC, Hamm RJ (1996) Estrogen affects performance of ovariectomized rats in a two-choice water-escape working memory task. Psychoneuroendocrinology 21:51-65.

Paganini-Hill A, Henderson VW (1994) Estrogen deficiency and risk of Alzheimer's disease in women. Am J Epidemiol 140:256-261.

Parpura V, Basarsky TA, Liu F, Jeftinija K, Jeftinija S, Haydon PG (1994) Glutamate-mediated astrocyte-neuron signalling. Nature 369:744-747.

Pelletier G, Liao N, Follea N, Govindan MV (1988) Mapping of estrogen receptor-producing cells in the rat brain by in situ hybridization. Neurosci Lett 94:23-28.

Pfaff D, Keiner M (1973) Atlas of estradiol-concentrating cells in the central nervous system of the female rat. J Comp Neurol 151:121-158

Rainbow TC, Parsons B, MacLusky NJ, McEwen BS (1982) Estradiol receptor levels in rat hypothalamic and limbic nuclei. J Neurosci 2:1439-1445.

Rissenberg M, Glanzer M (1986) Picture superiority in free recall: the effects of normal aging and primary degenerative dementia. J Gerontol 4:64-71.

Sherwin BB (1997) Estrogen effects on cognition in menopausal women. Neurology 48:S21-S26.

Shetty AK, Turner DA (1995) Intracerebroventricular kainic acid administration in adult rat alters hippocampal calbindin and nonphosphorylated neurofilament expression. J Comp Neurol 363:581-599.

Soriano E, Frotscher M (1993) GABAergic innervation of the rat fascia dentata: a novel type of interneuron in the granule cell layer with extensive axonal arborization in the molecular layer. J Comp Neurol 334:385-396.

Sulkava R, Wikstrom J, Aromaa A, Raitasalo R, Lehtinen V, Lahtela K, Palo J (1985) Prevalence of severe dementia in Finland. Neurol 35:1025-1029.

Tang MX, Jacobs D, Stern Y, Marder K, Schofield P, Gurland B, Andrews H, Mayeux R (1996) Effect of oestrogen during menopause on risk and age of onset of Alzheimer's disease. Lancet 348:420-421.

Toran-Allerand CD (1976) Sex steroids and the development of the newborn mouse hypothalamus and preoptic area in vitro: implications for sexual differentiation. Brain Res 106:407-412.

Trommald M, Jensen V, Andersen P (1995) Analysis of dendritic spines in rat CA1 pyramidal cells intracellularly filled with a fluorescent dye. J Comp Neurol 353:260-274.

Weiland NG, Orikasa C, Hayashi S, McEwen BS (1996) Localization of estrogen receptors in the hippocampus of male and female rats. Soc Neurosci Abstr 1:618.

Westrum LE, Blackstad TW (1962) An electron microscopic study of the stratum radiatum of the rat hippocampus (regio superior, CA1) with particular emphasis on synaptology. J Comp Neurol 119:281-292.

White WF, Nadler JV, Cotman CW (1979) Analysis of short-term plasticity at the perforant path-granule cell synapse. Brain Res 178:41-53

Williams CL (1996) Short-term but not long-term estradiol replacement improves radial arm maze performance of young and aging rats. Soc Neurosci Abstr 22:1164.

Woolley CS, McEwen BS (1992) Estradiol mediates fluctuation in hippocampal synapse density during the estrous cycle in the adult rat. J Neurosci 12:2549-2554.

Woolley CS, McEwen BS (1993) Roles of estradiol and progesterone in regulation of hippocampal dendritic spine density during the estrous cycle in the rat. J Comp Neurol 336:293-306.

Woolley CS, McEwen BS (1994) Estradiol regulates hippocampal dendritic spine density via an $N$-methyl-D-aspartate receptor-dependent mechanism. J Neurosci 14:7680-7687.

Woolley CS, Gould E, Frankfurt M, McEwen BS (1990) Naturally occurring fluctuation in dendritic spine density on adult hippocampal pyramidal neurons. J Neurosci 10:4035-4039.

Woolley CS, Weiland NG, McEwen BS, Schwartzkroin PA (1997) Estradiol increases the sensitivity of hippocampal CA1 pyramidal cells to NMDA receptor-mediated synaptic input: correlation with dendritic spine density. J Neurosci 17:1848-1859.

Youngjohn JR, Crook TH (1993) Learning, forgetting, and retrieval of everyday material across the adult life span. J Clin Exp Neuropsychol 15:447-460. 